\title{
Solitary Piloleiomyoma of the Scalp- A Rare Entity
}

\author{
Chaitra Dasareddy ${ }^{1}$, Zaheda Kausar², Anunayi Jeshtadi³, Triveni Bhopal ${ }^{4}$ \\ ${ }^{1}$ Department of Pathology, Osmania General Hospital, Hyderabad, Telangana, India. ${ }^{2}$ Department of Pathology, \\ Osmania General Hospital, Hyderabad, Telangana, India. ${ }^{3}$ Department of Pathology, Osmania General Hospital, \\ Hyderabad, Telangana, India. ${ }^{4}$ Department of Pathology, Osmania General Hospital, Hyderabad, Telangana, India.
}

\section{INTRODUCTION}

Leiomyomas are benign tumours of smooth muscles. They can occur in all places where smooth muscles are found. But, they are commonly encountered in uterus (also called as fibroid uterus), which is the most common location of leiomyomas. About $95 \%$ of all leiomyomas occur in uterus. The next common site is skin comprising about $3 \%-5 \%$ of all leiomyomas.[1,2] Cutaneous leiomyomas are rare and benign smooth muscle tumours of skin. According to the site of origin of smooth muscle, they are classified into Piloleiomyoma, Angioleiomyoma, Genital leiomyoma. Piloleiomyoma is the most common type primarily affecting the trunk and extremities. Solitary piloleiomyoma is more common in females. Here we present a case of a 45-year-old male patient, who presented with scalp swelling, diagnosed as piloleiomyoma on histopathology. The skin consists of smooth muscles as arrector pili muscles, smooth muscles in the wall of blood vessels, and specialized muscle in genital sites (i.e., scrotum [dartos], vulva, and nipple [areolar]).[3] These smooth muscles of skin give rise to cutaneous leiomyomas. On the basis of smooth muscle of origin, cutaneous leiomyomas are divided into five types- multiple piloleiomyomata, solitary piloleiomyoma (both arising from arrectores pilorum muscles), solitary genital leiomyoma (arising from the dartoic, vulvar, or mammillary muscles), solitary angioleiomyoma (arising from the muscles of veins) and leiomyoma with additional mesenchymal elements.[4]

\section{PRESENTATION OF CASE}

A 45-year-old male presented to the Surgery OPD with chief complaints of swelling over the scalp for 7 years. The swelling was not progressing in size with on and off complaints of pain. No other swellings noted in the body. On examination single, nodular swelling was present in the occipital region of scalp measuring $1.5 \mathrm{~cm}$ in diameter, firm in consistency, skin over the swelling was normal. The swelling was given the provisional diagnosis of sebaceous cyst and was excised. The specimen was sent in formalin for histopathological examination to the Department of Pathology.
Corresponding Author: Dr. Chaitra Dasareddy, Postgraduate,

Upgraded Department of Pathology, Osmania Medical College,

Koti, Hyderabad, Telangana, India.

E-mail: chaitradasareddy@gmail.com

DOI: $10.14260 / \mathrm{jemds} / 2019 / 828$

Financial or Other Competing Interests: None.

How to Cite This Article:

Dasareddy C, Kausar Z, Jeshtadi A, et al Solitary piloleiomyoma of the scalp- a rare entity. J. Evolution Med. Dent. Sci. 2019;8(50):3822-3824, $10.14260 /$ jemds $/ 2019 / 828$

Submission 09-08-2019,

Peer Review 27-11-2019,

Acceptance 03-12-2019,

Published 16-12-2019. 


\section{Gross Examination}

Received single grey brown, skin covered soft tissue mass measuring $2.5 \mathrm{~cm}$ in diameter. Cut section shows solid grey white nodule measuring $0.5 \mathrm{~cm}$ in diameter.

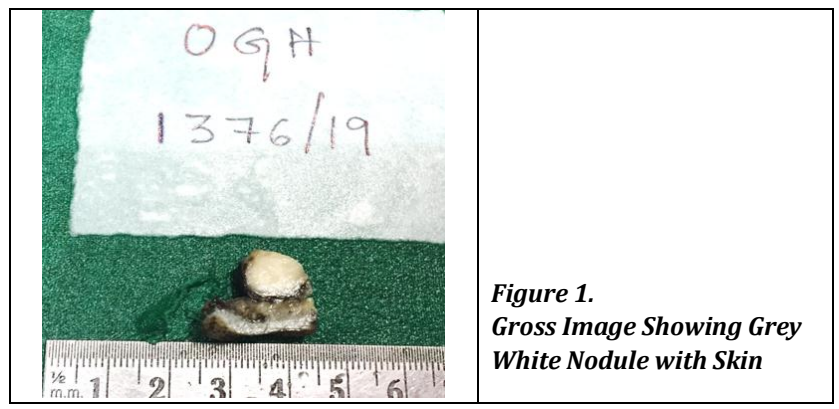

\section{Microscopic Examination}

$\mathrm{H} \&$ E stained section studied shows epidermis and dermis. Deep dermis shows well circumscribed tumour, arranged in bundles and fascicles. Individual tumour cells are spindle shaped and contain elongated spindle shaped nuclei with blunt edges. Low mitotic activity of $0-1 / 10$ HPF is seen.

\section{Impression}

Cutaneous leiomyoma- Pilar type

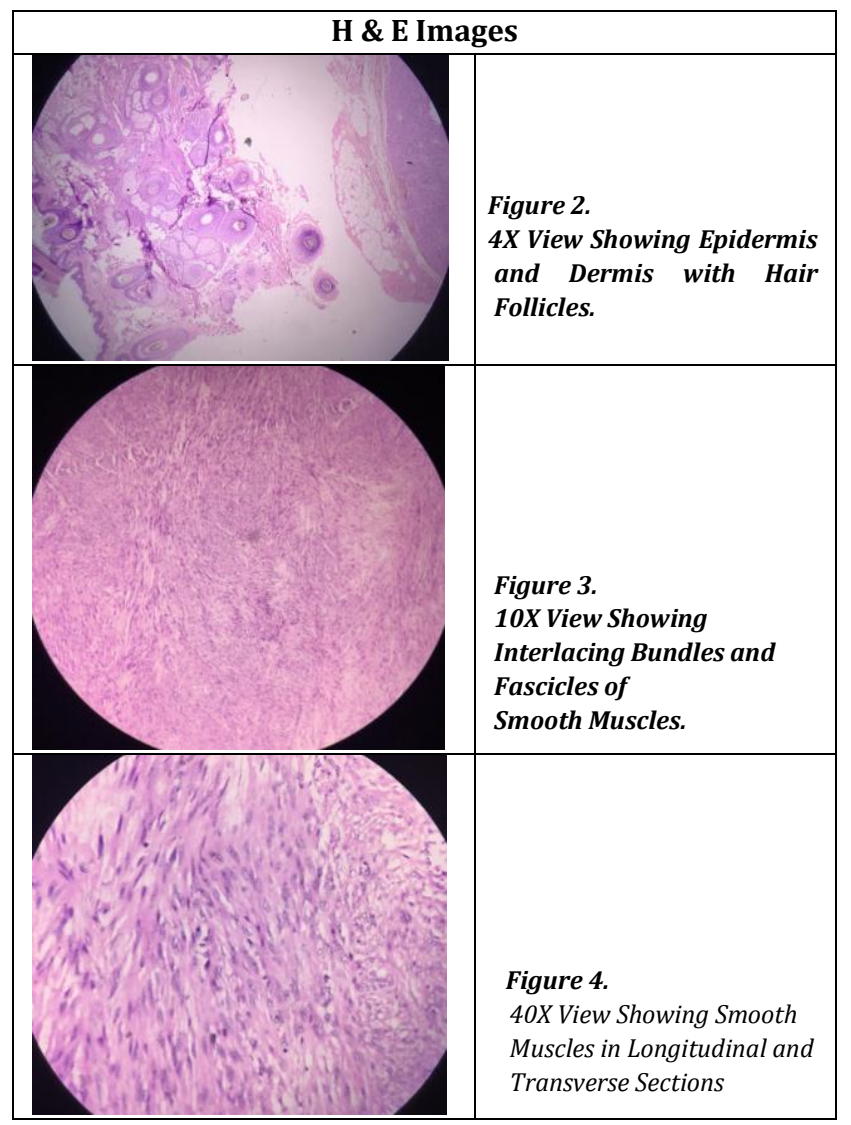

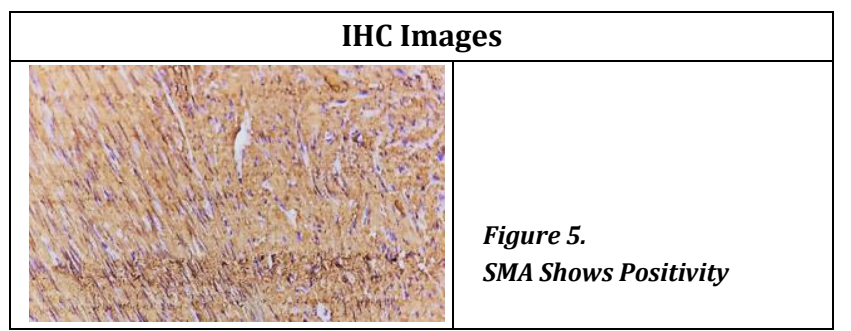

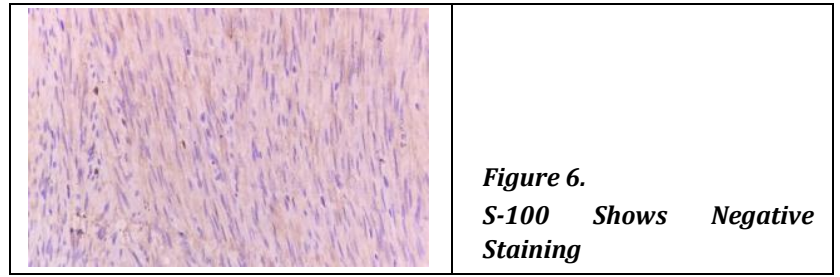

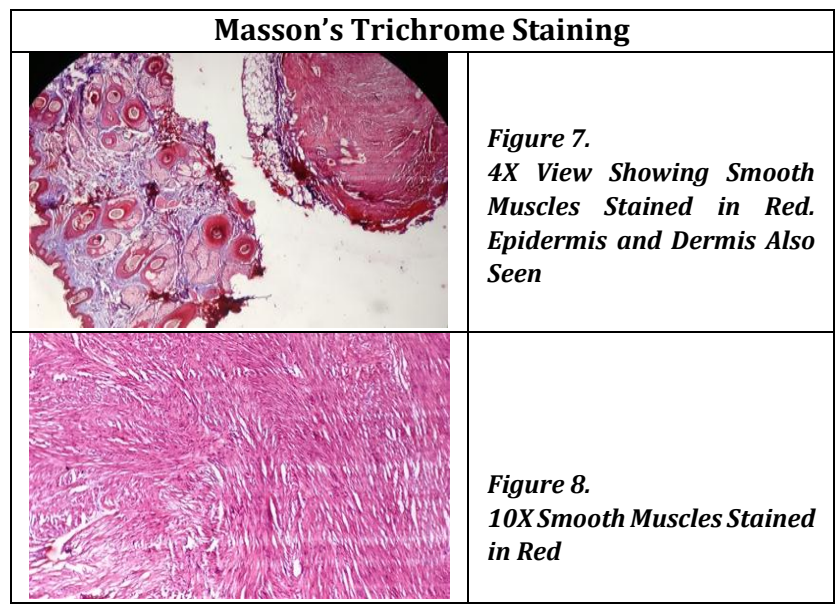

\section{DISCUSSION}

The most frequently encountered type of cutaneous leiomyoma is multiple piloleiomyomata. On examination they are seen as small, firm, red or brown intradermal nodules arranged in a group or linear pattern. They are commonly seen on the trunk and extremities. Usually they affect more than one areas. Usually, they are tender and can cause occasional painful paroxysms, which can be spontaneous or triggered by exposure to cold, pressure, trauma, or emotion.

Solitary piloleiomyomata differ from multiple piloleiomyomata in that they are single and are larger usually measuring up to $2 \mathrm{~cm}$ in diameter with female predominance. Congenital occurrence is rare. Most of them are tender and also occasionally painful. Genital leiomyomata occur in sites such as scrotum, labia majora, or, rarely, nipples. They arise from the dartoic, vulvar, or mammary smooth muscles. Unlike the above leiomyomas these are asymptomatic.

On histopathology, Piloleiomyomata, whether multiple or solitary, and genital leiomyomas have same features.

They are poorly demarcated and are composed of interlacing bundles and fascicles of smooth muscles within which varying amounts of collagen bundles are intermingled. They contain centrally located, thin, elongated, "cigar-shaped" nuclei with blunt-edges, and have a low mitotic activity of $<1$ per 10 highpower field (HPF).

Solitary angioleiomyomata are usually subcutaneous and only rarely intracutaneous lesions of the extremities. As a rule, they do not exceed $4 \mathrm{~cm}$ in diameter. Angioleiomyoma has a unique feature that with physical activity of the involved part, especially the hand, there is increase in size of the swelling. About $60 \%$ of cases, have chief complaints of painful mass.

In contrast to other types of leiomyomata, Angioleiomyomata are encapsulated and contain numerous vessels. Their numerous veins vary in size and have muscular walls of varying thickness, but do not have elastic lamina. 
Based on this, angioleiomyomas have been subclassified as a capillary or solid type, a cavernous type, and a venous type.

Hereditary leiomyomatosis and renal cell carcinoma syndrome is an autosomal dominant familial syndrome characterized by the development of uterine leiomyomata, cutaneous leiomyomata as well as aggressive renal tumours, most often of the papillary type. The mutation of this condition is fumarate hydratase (FH, 1q42.3-q43) gene.

Previously published case reports of cutaneous leiomyoma of scalp include the following- Dharm Chand Kothari et $\mathrm{al}^{3}$. reported a 22-year-old male with piloleiomyoma. Jung Ho Lee et al. reported a 31 year old male with solitary piloleiomyoma. A case of vascular leiomyoma of the scalp which was mimicking a dermoid cyst in a 6 year old boy was reported by Arishima et.al ${ }^{5}$.

\section{DISCUSSION OF MANAGEMENT}

If the cutaneous leiomyoma is single or in limited number, surgical excision is the treatment. When multiple, only larger lesions are excised. Analgesics are used for pain management

\section{CONCLUSIONS}

Cutaneous leiomyoma is diagnosed on histopathology rather than after clinical examination. Though the importance of diagnosing single cutaneous leiomyoma does not significantly affect the management of the patient, if it is seen in association with renal cell carcinoma and uterine fibroids, the patient probably has hereditary leiomyomatosis and renal cell carcinoma syndrome. This cutaneous leiomyoma can be an additional feature favouring the diagnosis of above syndrome. In routine cases, cutaneous leiomyoma of scalp can be considered as one of the differential diagnosis for papulonodular lesion in the scalp, however it is a rare possibility.

\section{REFERENCES}

[1] Goldblum JR, Folpe AL, Weiss SW. Benign tumors of smooth muscle. In: Goldblum JR, Weiss SW, Enzinger FM, eds. Enzinger and Weiss's Soft tissue tumors. $6^{\text {th }}$ edn. Philadelphia: Elsevier Saunders 2014: p. 524-48.

[2] Kim DH, Lee JS, Kim JA, et al. Solitary Piloleiomyoma in the scalp. Arch Craniofac Surg 2017;18(1):62-4.

[3] Fatima Q, Singh 0, Kothari DC, et al. Cutaneous leiomyoma of scalp: a rare case report with review of literature. International Journal of Research in Medical Sciences 2015;3(4):993-7. www.msjonline.org

[4] Elder DE. Lever's Histopathology of the Skin. $11^{\text {th }}$ edn. Lippincott Williams \& Wilkins 2014.

[5] Arishima H, Takeuchi H, Kitai R, et al. Vascular leiomyoma of the scalp with a small deformity on the skull mimicking a dermoid cyst. Pediatr Dermatol 2013;30(3):e27-9. 